\title{
APÓS MARIANA E BRUMADINHO: UMA ANÁLISE DISCURSIVA DE NOTÍCIAS SOBRE O DESCASO
}

\author{
Maria Lúcia Cunha Vitório de Oliveira ANDRADE ${ }^{1}$ \\ Celia Regina ARAES ${ }^{2}$
}

DOI: http://dx.doi.org/10.21165/gel.v18i3.3141

Resumo: O presente artigo objetiva identificar os processos avaliativos de julgamento dos comportamentos de empresários e representantes legais divulgados na mídia impressa sobre o rompimento de barragens nas cidades mineiras de Mariana e Brumadinho. $\mathrm{O}$ corpus é constituído por duas notícias veiculadas na Folha de S. Paulo em 2019, uma que aponta um alto lucro da mineradora Vale, considerada responsável pelos acidentes, e outra expondo a situação da população carente que ainda enfrenta falta de moradia e de emprego. Selecionou-se o Sistema de Avaliatividade como categoria de análise, sendo que este origina-se no arcabouço teórico-metodológico da Linguística Sistêmico Funcional, além de buscar apoio na Análise Crítica do Discurso e na Ecolinguística. Como uma antecipação de resultados, verifica-se que os interesses econômicos empresariais superam o bem-estar humano e a preservação ambiental.

Palavras-chave: Discurso. Mídia. Ecolinguística. Denúncia.

\footnotetext{
1 Universidade de São Paulo (USP), São Paulo, São Paulo, Brasil; maluvictorio@uol.com.br; http://orcid.org/0000-0002-3862-6573

2 Universidade de São Paulo (USP), São Paulo, São Paulo, Brasil; celia.araes@gmail.com; https://orcid.org/0000-0003-2613-646X
} 
- Após Mariana e Brumadinho: uma análise discursiva de notícias sobre o descaso

\title{
AFTERMARIANA AND BRUMADINHO: A DISCURSIVE ANALYSIS OF NEWS ABOUT NEGLECT
}

\begin{abstract}
This article intends to identify the evaluation processes of the judgment of entrepreneurs and legal representatives' behaviors published in the printed media about the rupture of dams in the mining towns of Mariana and Brumadinho. The corpus consists of two news published in Folha de S. Paulo in 2019, one talks about a high profit from mining company Vale, considered responsible for the accidents, and the other one exposes the situation of the disadvantaged population that still faces a lack of housing and jobs. The Appraisal System was selected as the category of analysis, which originates in the theoretical-methodological framework of Systemic Functional Linguistics, in addition to seeking support in Critical Discourse Analysis and Ecolinguistics. As an anticipation of the results, it notes that business economic interests surpass human well-being and environmental conservation.
\end{abstract}

Keywords: Discourse. Media. Ecolinguistic. Complaint.

\section{Introdução}

\author{
"Voltou seus olhares para aquilo tudo e me viu. Veio caminhando em minha \\ direção esperando o que eu ia falar. Eu não queria dizer nada. Abaixei a cabeça \\ e sussurrei: \\ - Não deu, tenente. O mar de lama levou." (FARAH, 2019, p. 73).
}

O conhecimento do percurso histórico das explorações do subsolo brasileiro contribui para compreender mais profundamente os acidentes ${ }^{3}$ nas cidades mineiras de Mariana e Brumadinho em novembro de 2015 e janeiro de 2019, envolvendo o nome da Vale. Nesse sentido, julga-se importante revisitar brevemente o objetivo financeiro da empresa, sendo que desde o final do século XIX, com a decadência da Era do Ouro, buscavam-se formas de extração de outros minérios. O estado de Minas Gerais continuava sob os olhares de quem procurava novas riquezas e, já na primeira década do século XX, o Pico do Cauê, na cidade de Itabira, tinha sido considerado a maior jazida de ferro do mundo e essa descoberta instigou a cobiça de investidores brasileiros e estrangeiros. A empresa inglesa Itabira Iron Ore Company foi a primeira a explorar os minérios da região,

\footnotetext{
3 Não é objetivo discutir se o ocorrido nas cidades mineiras em virtude das barragens foi realmente um "acidente", sendo assim, utilizar-se-á esse termo no presente trabalho como empregado nas fontes consultadas. A substituição do termo "acidente" por outro vocábulo demandaria uma análise decorrente de pesquisas distintas.
} 
mas, por não cumprir os termos contratuais no que se referia ao volume de ferro extraído anualmente, em 1942, pelo Decreto-Lei ${ }^{\circ} 4.352$, de $1^{\circ}$ de junho do mesmo ano, a posse das minas passou a ser, por direito, do governo brasileiro (GUIMARÃES, 1981). Contudo, deve-se destacar o papel fundamental da Itabira Iron para incorporar a Companhia Vale do Rio Doce (CVRD), em conjunto com a Companhia Brasileira de Mineração e Siderurgia S.A., com o poder de exploração e ampliação da estrada de ferro Vitória a Minas (EFVM). Isso facilitou o transporte do ferro do interior do país para o porto do Espírito Santo, tendo como alvo os negócios com os países estrangeiros de grande parte de toda a produção.

A CVRD foi criada ainda em 1942 pelo presidente Getúlio Vargas com o propósito de nacionalizar o minério e abastecer as indústrias siderúrgicas recém-implantadas no país. Entretanto, importava, fundamentalmente, alavancar o fornecimento de ferro para a indústria bélica americana, sendo, inclusive, uma forma de o Brasil atender às pressões políticas internas e externas para participar da Segunda Guerra Mundial. Ainda no final da mesma década, a mineradora já tinha $80 \%$ de sua produção voltada para a exportação e, até 2019, segundo o documento do Movimento dos Atingidos por Barragens - MAB (2019), o objetivo ainda era vender para esse mercado. No final da década de 1990, mesmo sob suspeita de fraudes, de acordo com a publicação no mesmo documento (MAB, 2019), o movimento de privatização foi fortemente questionado, mas o Poder Judiciário não finalizou a análise dos inquéritos e a privatização foi confirmada durante o governo de Fernando Henrique Cardoso. A fragilidade econômica no mundo todo, acentuada pela crise nos países asiáticos, não intimidou a CVRD que, mesmo passando pelo fim da estatização, tivera um lucro de $R \$ 1,02$ bilhão em 1998, o maior de todos em seus cinquenta e cinco anos de história até então. Após três anos da privatização, suas ações passariam a ser comercializadas na Bolsa de Valores de Nova York (NYSE) e, ao mesmo tempo em que entendia o comércio sob as novas ordens mundiais, propagava o respeito às ações ambientais, firmava parcerias atravessando os cinco continentes, conquistando, assim, o status da maior produtora de minério de ferro do planeta.

Tendo em vista facilitar a leitura visual e reforçar a imagem da empresa internacionalmente, em 2007, o nome foi alterado para Vale e o logo para a letra Vestilizada, o que poderia representar tanto uma cava de mina como um formato de coração. As mudanças não pararam por aí e a Vale, nos anos seguintes, diversificou os investimentos, ampliando as atividades mineradoras, e alçou voo em outros ramos da economia como na industrialização de fertilizantes e em empresas de logística, comprando e construindo navios para conseguir autonomia nos transportes de seus produtos. Isso garantiu não apenas o aumento do leque de investimentos e lucros, como permitiu maior fluxo nas exportações, sempre com o rótulo de uma mineradora que alcança lucros extraordinários, como exposto a seguir: 
- Após Mariana e Brumadinho: uma análise discursiva de notícias sobre o descaso

Ao longo dos quase 22 anos como empresa privada, a Vale se consolidou como uma das maiores mineradoras do mundo, com capital aberto e ações vendidas nas principais Bolsas de Valores. O principal objetivo da Vale é aumentar lucros e distribuir dividendos para os acionistas. (MAB, 2019, p. 13).

O acidente de Mariana contabilizou 19 mortes humanas e incontáveis mortes ambientais na região avizinhada, além de atingir os litorais capixaba e baiano. Não se trata de uma hipérbole quando se usa o termo "incontável" para definir a destruição que a Bacia Hidrográfica do rio Doce sofreu com o despejo de quase 50 milhões de metros cúbicos de lama contaminada de rejeitos da mineração, contendo minério de ferro e outros metais considerados pesados. Já em Brumadinho, foram 252 mortos e 18 desaparecidos, segundo os dados de Ragazzi e Rocha (2019), quando a barragem da mina Córrego do Feijão também se rompeu.

A Vale está presente na mídia, ora como uma empresa de grande representatividade financeira no cenário mundial, ora por ter seu nome envolvido em acidentes, rompimento de barragens, mortes e desastres ambientais. Para este artigo, a seleção de dois textos jornalísticos (anexos) que foram publicados no mesmo ano, 2019, inclusive ano do acidente de Brumadinho, deve-se exatamente pela dualidade dessas situações. Por um lado, em 27 de março, a Folha de S. Paulo noticia o lucro de mais de 25 bilhões de reais da empresa, matéria assinada por Nicola Pamplona (TEXTO 1) e, por outro, em 05 de novembro, o descaso com os vitimados das duas cidades palco dos acidentes das barragens é contado por Fabiano Contarato (TEXTO 2) no mesmo jornal.

Nesse cenário de riqueza e sofrimento, objetiva-se uma leitura atenta entre as notícias na busca por identificação dos processos avaliativos de julgamento dos atores sociais ${ }^{4}$ envolvidos diretamente nos acidentes, aqueles considerados responsáveis pela regulamentação e recuperação dos locais destruídos, estabelecendo um grau de positividade e negatividade de seus comportamentos diante dos fatos. Dessa forma, espera-se reconhecer nas descrições linguísticas se há assimetria nas relações de poder nos discursos midiáticos analisados.

A opção por textos veiculados no mesmo jornal permite uma leitura comparativa, dirimindo as variáveis de cunho ideológico, pois já há uma proposição diferenciada de pauta e de datas entre os textos selecionados. A análise está apoiada nas partes mais

$4 \mathrm{O}$ termo "atores sociais" está sendo utilizado como proposto pela Teoria de Representação dos Atores Sociais (VAN LEEUWEN, 2008) ao revelar uma preocupação sociológica na forma de sua manifestação de inclusão ou exclusão discursiva. As escolhas para fazer as referências textuais estabelecem uma relação de poder entre os participantes do discurso. 
relevantes de descrição dos julgamentos, assim como os títulos e subtítulos de cada notícia.

Salienta-se, de antemão, que em nenhum dos dois textos jornalísticos houve um debate aberto com os responsáveis pelos acidentes, considerando, assim, para análise, os reflexos dos discursos representativos na grande mídia.

\section{Fundamentação teórica}

Diante da degradação crescente do meio ambiente, inclusive ameaçando a continuidade da vida na face da Terra, nada mais indicado do que cada cientista assumir uma postura de defesa dela. (COUTO, 2015, p. 174).

Como o tema retrata questões ambientais, busca-se apoio na Ecolinguística, um estudo das relações entre língua e ecologia, que ganhou maior notoriedade no mundo acadêmico graças aos movimentos de conscientização sobre os problemas da natureza. Não se pode afirmar que essa disciplina considera apenas os temas ambientais na busca de compreender o discurso dos poluidores que se mostram amigos do meio ambiente, mas, segundo Couto (2015), cerca de $62 \%$ dos textos das coletâneas publicadas se dedicam a esse tipo de questão.

O maior objeto de estudos da Ecolinguística está baseado nas relações entre língua e meio ambiente, que compreende o meio ambiente social e natural. O primeiro diz respeito ao social (efetivamente), psíquico, cognitivo ou mental e ideológico. O natural engloba o território e a fauna, a flora, o ar, os rios e tudo mais que está relacionado a ele. Afirma-se que a diversidade é maior do que a unicidade e o princípio supremo desse estudo é o reconhecimento da diversidade, incluindo, então, a biodiversidade.

Um dos estudiosos da Ecolinguística, Fill (2015), considera que o pensamento unidimensional leva a acreditar que o tamanho de algo define sua utilidade, por exemplo, equipara os termos "grande" e "bom". Esse tipo de pensamento sobre a língua pode ser percebido a partir das escolhas lexicais que conotam os usos pejorativos ou negativos de uma determinada situação, inclusive, o termo "growthism" foi utilizado para explicar esse fenômeno linguístico de valorização do que é grande e tudo que ideologicamente pode representar crescimento e desenvolvimento. Sendo assim, essas formas de exposição das grandezas devem ser desveladas a fim de conscientizar os usuários das línguas de que algumas delas, muitas vezes enraizadas culturalmente, podem representar discursos preconceituosos, mesmo que, aparentemente, possam indicar aspectos positivos de cuidados com os fatores bióticos e abióticos. 
- Após Mariana e Brumadinho: uma análise discursiva de notícias sobre o descaso

Grosso modo, a Análise Crítica do Discurso (ACD), calcada na visão funcionalista da linguagem, estreita a relação entre as estruturas linguísticas de um texto e a participação social dos indivíduos em uma comunhão de significados e usos discursivos. A linguagem é tida como uma forma de intervenção na ordem social e econômica, por isso, os textos que abordam os conceitos de poder e de dominação são contemplados nesses estudos. Fairclough (2001) tem como foco de estudo um problema social e, nesse sentido, considera o discurso como constituinte da expressão de uma pessoa, pois seu discurso é uma forma de sua emancipação social. O grande diferencial proposto pela ACD é ter elegido a língua como prática social, uma espécie de autorregulação da sociedade. Não à toa, a Ecolinguística e a ACD podem ser consideradas complementares em seus estudos e propósitos, tendo a denúncia de injustiças como um norteador temático. Exemplo disso, voltando ao tema do corpus deste artigo, a Ecolinguística e a ACD são trazidas à ação para uma análise das estratégias discursivas com a exposição dos altos índices de lucro da Vale e as condições desfavoráveis de como vivem os vitimados dos acidentes cuja responsabilidade está atribuída a essa mesma empresa.

Como aporte para análise do corpus, o Sistema de Avaliatividade (SA) de Martin e White (2005), concebido a partir de Linguística Sistêmico Funcional (LSF) proposta por Halliday e Mathiessen (2004), auxiliará este trabalho por enfatizar a funcionalidade da linguagem e preocupar-se com questões sociais realizando avaliações dos posicionamentos dos falantes/escritores. Essas avaliações, segundo Martin e White (2005), revelam sentimentos, valores e crenças que constroem identidades dos falantes/escritores e, sendo assim, entram em harmonia, ou não, com a sociedade em que estão inseridos. Na construção de enunciados, é possível fazer escolhas a partir de diversas possibilidades que estão à disposição no sistema linguístico e isso revela um posicionamento de valor do indivíduo em percepção de si mesmo e do mundo.

O SA consiste em três grandes categorias que são denominadas de Atitude, Engajamento e Gradação e suas subcategorias. A Atitude subdivide-se em Afeto, Julgamento e Apreciação. O Afeto traz à tona formas de sentimento através das reações emocionais, o Julgamento avalia comportamentos ligados às pessoas e a Apreciação está ligada à estética impressa sobre as entidades.

A segunda categoria é o Engajamento, uma forma de reconhecer o posicionamento da voz autoral no texto ou de trazer vozes não-autorais para o texto, "trazer perspectivas intersubjetivas disponíveis" (NININ; BARBARA, 2013, p. 129). Nessa categoria, os enunciados podem assumir uma característica monoglóssica ou heteroglóssica. Estas também possuem subcategorias que auxiliam a análise dos discursos. Os monoglóssicos são enunciados que reduzem ou apagam as redes dialogais entre textos, enquanto os 
heteroglóssicos expõem posicionamentos alheios em uma rede dialogal. Estes últimos ainda podem revelar a expansão dialógica (permitem efeitos de aceitabilidade de outros textos) ou de contração dialógica (reduzem efeitos de posicionamentos autorais).

A Gradação é a terceira categoria do Sistema que está ligada aos graus de valores em relação à intensidade de ocorrência dos fenômenos e pode ser subdividida em Força e Foco. A Força imprime um grau de intensidade ou quantidade à voz autoral e se manifesta em um único item lexical ou se faz necessária a presença de um intensificador para graduar o processo ou a qualidade. O Foco, considerado como não-escalar, pode ser percebido pelo reforço ou suavização da voz em relação às categorias com que opera. Segundo Souza (2010), a subcategoria do Foco permite que os falantes expressem diferentes graus de prototipicalidade experiencial, representação de um elevado ou diminuto grau de autenticidade.

Para este artigo destacamos, na categoria de Atitude, o Julgamento que se apresentou com maior relevo durante a leitura e, posteriormente, classificamos os comportamentos nos padrões de sanção ou de estima social. Ainda foi possível a identificação da Força e do Foco que fazem parte da subcategoria de Gradação e aqui, vale ressaltar, como apresentado no estudo da Ecolinguística, a intensificação das qualidades das empresas como uma característica sine qua non nos textos que trazem números e estatísticas dos lucros. O uso de comparativos de superioridade e superlativos encaminham para, em uma primeira interpretação, pontos positivos da Vale e dos órgãos governamentais, mas, através de uma leitura mais aprofundada, esses pontos podem ser relidos sob outra ótica.

\section{A análise dos comportamentos da Vale e dos representantes da lei}

Inconteste dizer que a segurança de barragens e a gestão de riscos de desastres são negligenciadas no Brasil. A fiscalização é ridícula. (CONTARATO, 2019, p. 2).

O uso do sistema linguístico permite a realização de uma avaliação sobre o comportamento dos indivíduos e suas representações em consonância com os diversos modos de agir dos atores sociais associado ao seu caráter ou à sua personalidade através de normas sociais de conduta. A sociedade estipula padrões de comportamento com base em suas leis, valores, crenças e preceitos a partir do que considera correto ou incorreto e exerce um julgamento com o intuito de aprovar ou desaprovar as atitudes dos sujeitos. Na visão de Martin e White (2005), o julgamento pode gerar críticas, admiração ou condenação e, nesse sentido, insere-se em subcategorias de estima social 
- Após Mariana e Brumadinho: uma análise discursiva de notícias sobre o descaso

ou sanção social a depender da normalidade, capacidade e tenacidade quanto à estima ou veracidade e propriedade no que diz respeito à sanção.

Nesse contexto social, marcado por dados históricos, culturais e ideológicos, os comportamentos são avaliados em uma gradação positiva ou negativa. GonçalvesSegundo (2011) considera que a estima social integra valores relacionados ao convívio mais íntimo entre os sujeitos ligados aos processos básicos de integração social, portanto, são julgamentos em que não cabem punições institucionais. Para a sanção social, o mesmo autor considera que ela está relacionada a atitudes de louvor/destaque ou condenação/ recriminação. A sanção social envolve questões legais, jurídicas, de ética e de honestidade dentro de parâmetros impostos pela sociedade, portanto, são julgamentos variáveis de uma cultura para outra que devem ser cumpridos e/ou obedecidos.

Quanto à empresa Vale, no TEXTO 1, os números relacionados ao balanço da empresa realizado anualmente chega a bilhões de reais, potencializado por números na casa de centena de bilhões ao falar de receita e porcentagens representativas de adição, aparecem associados ao valor que a empresa Vale tem. A informação está centrada no termo "lucro" que carrega um sentido de acúmulo desse valor e o processo material (HALLIDAY; MATHIESSEN, 2004) "fecha", isto é, propõe a finalização de um ciclo após as contas de 2018 e, ao mesmo tempo, por estar no presente do indicativo, parece dar estabilidade dessa riqueza e continuidade da conquista do valor atribuído à empresa, como se pode ler no decorrer de todo o texto e na manchete e linha fina descritas a seguir:

- Manchete: Vale lucra $\mathrm{R} \$ 25,6$ bi em balanço ainda sem efeitos de Brumadinho

- Linha fina: Empresa fecha 2018 com receita de R $\$ 134$ bilhões, 24\% acima de 2017 (PAMPLONA, 2019)

Nesse caso, o jornal atribui um julgamento com aspectos positivos quanto à capacidade da empresa, características essas pertinentes ao gênero da demonstração financeira de empresas bem-sucedidas financeiramente, gerando no leitor uma sensação de estima social da Vale. Se por um lado, o comentário que vem como aposto "ainda sem efeitos de Brumadinho" corrobora positivamente para a interpretação de riqueza da empresa que não teve perdas até aquele momento mesmo após o acidente, por outro, o fato de o acidente ser citado na manchete, faz o leitor lembrar de um elemento de carga negativa, expondo - assim - a dualidade da situação entre o lucro e o acidente.

Em quatro parágrafos do total de dezesseis, ideias contraditórias sobre as ações da Vale podem gerar dúvidas em relação aos lucros e pagamentos realizados para indenizações. Nos parágrafos três e quatro, em discursos relatados, a voz atribuída à 
Vale (empresa) e não a um representante dela diz estar ainda em processo de avaliação da situação após acidente e que não é possível determinar um conjunto de resultados e estimativas confiáveis, além de justificar os custos que teve naquele determinado período com doações, indenizações, equipamentos, consultores jurídicos, entre outros. O documento do balanço ainda cita gastos de $\mathrm{R} \$ 5$ bilhões para descaracterizar barragens com alteamento a montante com as barragens de Mariana e Brumadinho, no parágrafo cinco. Nos dois últimos parágrafos (quinze e dezesseis), o texto traz, através da voz do ex-presidente Fabio Schvartsman, que atuou de maio de 2017 até fevereiro de 2019, um anúncio da suspensão de pagamento de dividendos e de processo de recompra de ações. Porém, na parte final que traz a voz autoral do jornal, a informação é de que, como mostrado no balanço de 2018, a companhia já havia distribuído mais de $25 \%$ do lucro líquido obrigatório por lei aos acionistas. A informação do jornal ainda relata que foram pagos $\mathrm{R} \$ 7,7$ bilhões a título de juros sobre o capital próprio e revela a voz da Vale, inclusive apresenta uma parte entre aspas, dizendo que o volume é significativamente acima do limite legal. Nesse caso, as informações parecem controversas e colocam em xeque a veracidade das vozes autorais, expressando um posicionamento de desaprovação do comportamento da Vale.

No TEXTO 2, publicado na mesma data em que se completavam quatro anos do acidente de Mariana, mesmo que aparentemente os termos "descaso" e "omissão" usados na manchete estejam associados à cidade de Mariana, não são atributos dessa cidade. O julgamento, na realidade, é de um sujeito ausente do enunciado; "descaso" e "omissão" são atitudes da Vale na ocasião dos acidentes e de seu comportamento com os vitimados pós-acidente. Os posicionamentos de valor nem sempre estão explícitos no texto, como assevera Martin (2001), e o reconhecimento dessas avaliações deve ser realizado a partir de marcas que revelam a intencionalidade dos falantes/escritores ligados à interpretação dos ouvintes/leitores de acordo com os contextos de interação. Destacam-se a manchete e a linha fina a seguir:

- Manchete: Após quatro anos, Mariana vive descaso e omissão

- Linha fina: Demora nas respostas do Legislativo é devastadora

Cabe o julgamento de sanção social da empresa Vale com acento valorativo de negatividade. A Vale impôs uma situação desfavorável aos moradores de Mariana e essa condição é acentuada pelo verbo "viver", identificando a continuidade do processo sem atuação da Vale para a melhoria da vida desses moradores.

Além da Vale, há um julgamento do Poder Legislativo na linha fina que aponta para uma desaprovação de comportamento de quem é responsável pela elaboração e 
- Após Mariana e Brumadinho: uma análise discursiva de notícias sobre o descaso

aprovação da lei, considerada "devastadora" no que concerne à demora nas respostas. Essa informação é retomada no último parágrafo (dez) justificando os efeitos negativos para a população porque os decretos propostos (descritos no decorrer do texto) não foram aprovados. O sentimento de medo de uma nova tragédia pela omissão da legislação é claramente expresso nesse trecho com a afirmação de que é preciso uma "ação de verdade" (CONTARATO, 2019). Há nessa fala uma reprovação do comportamento de políticos que se consideram novos e que não são, segundo o texto do jornal. O enunciado "O porquê de não confiarmos que, no futuro, poderemos evitar 'novas Marianas'" traz o sentimento coletivo com o uso da primeira pessoa do plural na conjugação verbal, ou seja, o jornal compartilha a desconfiança com seu leitor e, mais uma vez, coloca as atitudes da Vale em xeque por não creditar ou confiar em um futuro seguro.

O julgamento de estima social revela um padrão em textos que apresentam balanços financeiros de empresas lucrativas com a potencialização de elementos de Gradação, ou seja, essa subcategoria reforça a ideia de quão capaz a empresa é e quanto de crescimento e desenvolvimento isso representa. As escolhas de termos evidenciam os indicadores de gradação no eixo da força (intensidade e qualidade) no TEXTO 1, veiculado em março, que demonstram os altos índices de lucro, como na linha fina o uso da expressão "acima" na comparação de porcentagens de dois anos consecutivos. No parágrafo oito, "O desempenho da companhia em 2018 foi beneficiado [...], que amplia a receita em moeda nacional de produtos vendidos no mercado internacional." (PAMPLONA, 2019), os termos "beneficiado" e "amplia", apesar de pertencerem a classes gramaticais diferentes, qualificam positivamente o desempenho da Vale.

Outra manifestação de gradação é a repetição de números que contabilizam bilhões retratados por várias vezes no decorrer do texto. Em sucessivos parágrafos ocorrem as informações que conotam riqueza, inclusive no parágrafo nove há uma retomada da linha fina. É o caso que quantifica o lucro no parágrafo oito que retrata a receita, a geração do caixa no parágrafo nove, a demonstração de variação cambial e volume de vendas no parágrafo dez e a produção em toneladas no parágrafo onze.

No TEXTO 2, de novembro, os índices numéricos que expressam grande quantidade, na casa de milhões, estão ligados ao derramamento da lama e ao percurso que ela fez em quilômetros, como descrito no primeiro parágrafo. Outra grandeza desse trecho referese às pessoas afetadas, que contabilizam milhares, segundo o texto. Em outras partes do texto, os números aparecem em forma de denúncias, como no quinto parágrafo. O jornal dá voz ao ministro de Minas e Energia, Bento Albuquerque, que, em discurso direto, afirma não haver barragens seguras em depoimento de que apenas 16 profissionais fiscalizavam 790 barragens em todo o país. 
Uma oposição entre "muito" e "pouco" opera um processo de Gradação no julgamento do Congresso Nacional, no parágrafo oito, ao comparar a quantidade de discurso de parlamentares (grande quantidade) e quase nenhuma deliberação dos documentos (pouca quantidade). Esses quantificadores estão presentes em outras partes, como no momento em que é descrito o que ocorre nas audiências públicas com a ausência dos senadores nas sessões (poucas pessoas), quando, na opinião do jornal, a presença deveria ser dos dezessete titulares e dezessete suplentes (todas as pessoas). Ainda, no terceiro parágrafo, continuando o assunto do parágrafo anterior, a descrição dos recursos (considerados pouquíssimos), qualificando as famílias das vítimas como pobres e carentes também revela oposição à riqueza da mineradora (considerada grande). No mesmo fragmento, a gradação de foco revela a oposição de poder, que por um lado expõe a fragilidade das famílias e por outro revela a fortaleza do judiciário e empresários na expressão "titãs do direito e altos executivos".

Recapitulando o conceito de que o Julgamento está ligado às atitudes das pessoas, avaliando a ética, o caráter e como essas pessoas se comportam inseridas em uma determinada sociedade, entende-se o porquê de o Julgamento ser a subcategoria mais presente nos textos do corpus selecionado para a análise. É através do Julgamento que se pode reconhecer o modo como uma pessoa age e reage frente a uma situação em determinados contextos sociais. Aqui, neste artigo, a pessoa é simbolizada pela empresa e pelos órgãos reguladores públicos na representação dos atores sociais, a Vale e o Poder Legislativo.

Nos dois textos, os autores apresentam seus posicionamentos sobre o comportamento da mineradora diante dos acidentes. Mesmo no TEXTO1, com a descrição do desenvolvimento financeiro, há valoração de cunho negativo das atitudes empresariais. No TEXTO 2, até por uma característica genérica, a presença de críticas negativas feitas à empresa é mais explícita. As escolhas lexicais acompanhadas dos sentidos semânticos e sintáticos, como os exemplos citados dos tempos de conjugação verbal e palavras de conotação de grandezas, possibilitam ao leitor perceber que a Vale e os governantes são incapazes de resolver os problemas causados à população moradora de Mariana e Brumadinho, assim como de todas as cidades atingidas pelos dois rompimentos em questão e pela destruição da natureza por onde a lama se concentrou ou os caminhos que percorreu. O Julgamento de sanção social caracteriza inclusive aquilo que ainda não aconteceu de fato, avalia negativamente a falta de segurança que gera medo pelas atitudes de não aprovação de nova legislação.

Os atores sociais, manifestados em situação de assimetria de poder nos textos analisados e as instâncias de decisão representadas pelo coletivo (ativos), não cumprem 
- | Após Mariana e Brumadinho: uma análise discursiva de notícias sobre o descaso

seu papel social de recuperação das áreas vitimadas. Por outro lado, os atores (passivos) que sofreram a invasão da lama em suas vidas estão à espera de decisões. Portanto podemos, resumidamente, classificar os atores sociais em "aqueles que decidem" e "aqueles que esperam as decisões".

\section{Considerações finais}

Como proposta inicial, este artigo buscou reconhecer os processos avaliativos de julgamento dos sujeitos envolvidos nos acidentes de Mariana e Brumadinho presentes em duas notícias veiculadas na Folha de S. Paulo em 2019.

Os textos analisados trazem formas diferenciadas de abordar o comportamento de pessoas e instituições envolvidas no rompimento das barragens, representando sanções e estimas sociais. A empresa Vale está numericamente mais presente quando associada às avaliações negativas caracterizadas, majoritariamente, por questões de ética no auxílio aos vitimados. Nesse julgamento, uma avaliação positiva diz respeito às conquistas econômicas e financeiras da empresa especialmente quando analisado o discurso do TEXTO 1, de março de 2019.

Os julgamentos com polaridade negativa foram associados aos órgãos reguladores de leis, especialmente citados no TEXTO 2, de novembro de 2019, a julgar as atitudes do Poder Legislativo que, por não aprovar leis, causa medo coletivamente à população pelas incertezas de que um novo acidente possa acontecer, ou seja, um discurso de denúncia.

Percebe-se com a leitura dos dois textos uma assimetria de poder nos discursos dos atores sociais de acordo com os papéis que ocupam na sociedade, com pouca observância para o sofrimento das vítimas e atuação mínima para restabelecimento do modo de vida das pessoas e do meio ambiente. A mineradora Vale e o poder público detêm conjuntamente o poder econômico e legal e agem com descaso para com os problemas dos vitimados, moradores e meio ambiente atingido pelo rompimento das barragens por mais de uma vez.

\section{Referências}

CONTARATO, F. Após quatro anos, Mariana vive descaso e omissão. Disponível em: https://www1.folha.uol.com.br/opiniao/2019/11/apos-quatro-anos-mariana-vivedescaso-e-omissao.shtml. Acesso em: 05 nov. 2019. 
COUTO, H. H. do. Ecolinguística: estudo das relações entre língua e meio ambiente.

Brasília: Thesaurus Editora, 2007. Disponível em: www.thesaurus.com.br. Acesso em: 14 mar. 2020.

COUTO, H. H. do. Língua e meio ambiente. Revista de estudos da linguagem, v. 17, n. 1, p. 143-178, 2015. Disponível em: http://www.periodicos.letras.ufmg.br/index.php/relin/ article/view/2524. Acesso em: 04 abr. 2020.

FARAH, L. Além da lama: o emocionante relato do capitão dos bombeiros que atuou nas primeiras horas da tragédia em Mariana. São Paulo: Editora Vestígio, 2019.

FILL, A. F. Ecolinguística: a história de uma ideia verde para o estudo da linguagem. Ecolinguística: Revista Brasileira de Ecologia e Linguagem, v. 1, n. 1, p. 07-21, 2015 Disponível em: https://periodicos.unb.br/index.php/erbel/issue/view/918. Acesso em: 04 abr. 2020.

GUIMARÃES, J. E. P. Epítome da história da mineração. São Paulo: Art Editora, 1981.

\section{GONÇALVES-SEGUNDO, P. R. Tradição, dinamicidade e estabilidade nas práticas}

discursivas: um estudo da negociação intersubjetiva na imprensa paulistana. 2011. Tese (Doutorado em Filologia e Língua Portuguesa) - Faculdade de Filosofia, Letras e Ciências Humanas, Universidade de São Paulo, São Paulo, 2011. DOI: http://dx.doi. org/10.11606/T.8.2011.tde-25042012-161141

HALLIDAY, M.; MATHIESSEN, C. Introduction to Functional Grammar, 3. ed. London: Hodder Arnold, 2004.

MARTIN, J. Beyond Exchange: Appraisal systems in English. In: HUSTON, S.; THOMPSON, G. (ed.). Evaluation in text. Oxford: Oxford University Press, 2001.

MARTIN, J.; WHITE, P. The language of evaluation: appraisal in English. New York/ Hampshire: Palgrave Macmillan, 2005.

NININ, M. O. G.; BARBARA, L. Engajamento na perspectiva linguística sistêmico funcional em trabalhos de conclusão de curso de Letras. Trab. Ling. Aplic., Campinas, v. 52, n. 1, p. 127-146, jan./jul. 2013. DOI: http://dx.doi.org/10.1590/S0103-18132013000100008-146. 
- Após Mariana e Brumadinho: uma análise discursiva de notícias sobre o descaso

ORGANIZAÇÕES Movimento dos Atingidos por Barragens (MAB). O lucro não vale a vida. Secretaria Nacional: São Paulo, Brasil, 2019. Disponível em: https://issuu.com/ mabnacional/docs/cartilha-brumadinho-2019-web. Acesso em: 20 ago. 2020.

PAMPLONA, N. Vale lucra $\mathbf{R} \mathbf{2 5 , 6}$ bi em balanço ainda sem efeitos de Brumadinho. Disponível em: https://www1.folha.uol.com.br/mercado/2019/03/vale-lucra-r-256-biem-balanco-ainda-sem-efeitos-de-brumadinho.shtml. Acesso em: 27 mar. 2019.

RAGAZZI, L.; ROCHA, M. Brumadinho: A engenharia de um crime. Belo Horizonte: Letramento, 2019.

SOUZA, A. A. Gradação: força e foco. In: VIAN JR., O.; SOUZA, A. A. de; ALMEIDA, F. S. D. P. A linguagem de avaliação em língua portuguesa: Estudos sistêmico-funcionais com base no Sistema de Avaliatividade. São Carlos: Pedro e João Editores, 2010.

VALE. Nossa história. Rio de Janeiro. Verso Brasil Editora, 2012. Disponível em: http://www.vale.com/brasil/pt/aboutvale/book-our-history/paginas/default.aspx. Acesso em: 20 set. 2019.

VAN LEEUWEN, T. J. Discourse and Practice: New Tools for Critical Discourse Analysis. Oxford: University Press, 2008. 


\section{Anexos}

\section{Texto 1}

Vale lucra $\mathbf{R} \$ 25,6$ bi em balanço ainda sem efeitos de Brumadinho

Empresa fecha 2018 com receita de R\$134 bilhões, 24\% acima de 2017

27.mar.2019 às $20 h 19$

\section{Nicola Pamplona RIO DE JANEIRO}

$1^{5}$ - A Vale fechou 2018 com lucro líquido de $R \$ 25,6$ bilhões, alta de 45,5\% com relação ao registrado no ano anterior. Divulgado com uma fita preta de luto impressa na capa, o balanço da companhia não trouxe ainda impactos da tragédia de Brumadinho (MG), que ocorreu no dia 25 de janeiro.

2 - A companhia diz que os impactos serão contabilizados no primeiro trimestre de 2019. Até o momento, autoridades contabilizam 216 mortos e 89 desaparecidos. Com maiores restrições de segurança, minas com capacidade para produzir 92,8 milhões de toneladas por ano estão fora de operação.

3 - "A Vale ainda está avaliando os passivos potenciais que podem surgir da ruptura da Barragem I. Devido ao estágio preliminar das diversas alegações e contingências, não é possível determinar um conjunto de resultados ou estimativas confiáveis da exposição potencial", diz a empresa, no relatório.

4 - "Os custos incorridos até o momento são principalmente relacionados a doações, indenizações iniciais, assistência humanitária, equipamentos, consultores jurídicos, entre outros", completa.

5 A numeração feita nos parágrafos dos Texto 1 (1 a 16) e Texto 2 (1 a 10) não estava originalmente nos jornais consultados. As autoras optaram por numerar os parágrafos no item Anexos por considerar um recurso didático para melhor orientação na leitura do presente artigo. 
- | Após Mariana e Brumadinho: uma análise discursiva de notícias sobre o descaso

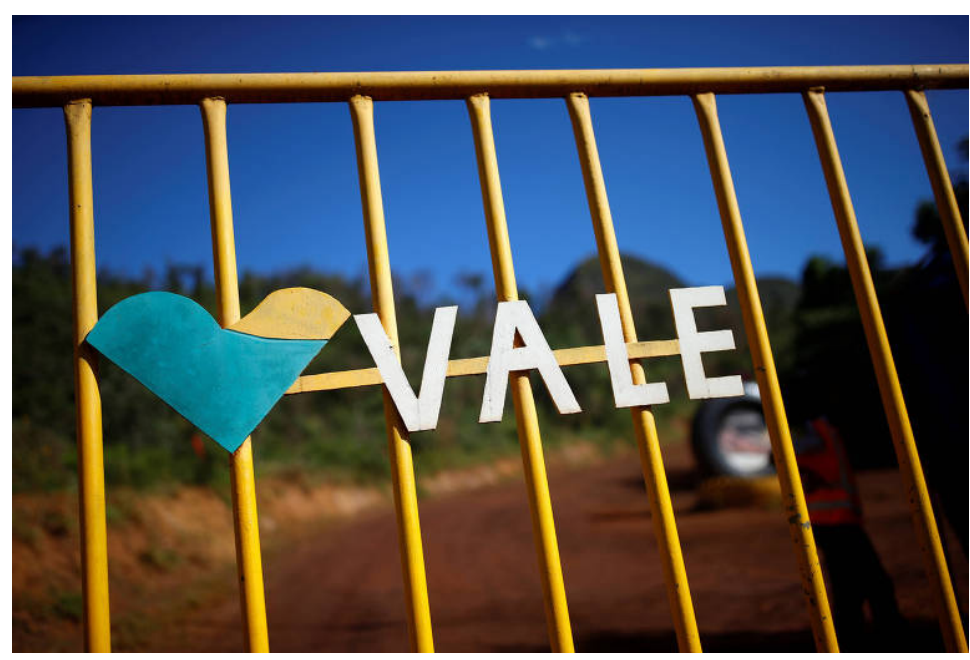

Logo da mineradora Vale em Brumadinho, Minas Gerais - Adriano Machado/Reuters

5 - O documento cita ainda gastos adicionais de $\mathrm{R} \$ 5$ bilhões para descaracterizar barragens com alteamento a montante, com as de Brumadinho e Mariana (MG), que se rompeu em 2015, deixando 19 mortos e um rastro de destruição que chegou ao litoral capixaba.

6 - A empresa diz também que dará baixa no valor dos ativos da mina Córrego do Feijão, onde estava a barragem que se rompeu em Brumadinho, e de outros ativos relacionados a barragens a montante no Brasil, "resultando em uma perda contábil, que impactará o balanço patrimonial e a demonstração do resultado da companhia".

7 - A divulgação do resultado de 2018 foi adiada após a tragédia de Brumadinho. Ao contrário de anos anteriores, a mineradora optou por arquivar os documentos na CVM (Comissão de Valores Mobiliários) depois do fechamento do mercado -e não no início do dia. Também não distribuiu vídeos de executivos comentando o resultado.

8 - O desempenho da companhia em 2018 foi beneficiado pela desvalorização do real ante do dólar durante o ano, que amplia a receita em moeda nacional de produtos vendidos no mercado internacional. Apenas no quarto trimestre, a Vale lucrou $R \$ 14,5$ bilhões, alta de $472 \%$ com relação ao mesmo período do ano anterior.

9 - A empresa fechou o ano com receita de $\mathrm{R} \$ 134$ bilhões, $24 \%$ acima do registrado em 2017. O Ebitda (medida que mede a geração de caixa de uma empresa) cresceu $24,6 \%$, para $\mathrm{R} \$ 61$ bilhões.

10 - Responsável por operações como a de Brumadinho, a área de Minerais Ferrosos teve Ebitda de $\mathrm{R} \$ 54,2$ bilhões, $25 \%$ a mais do que no ano anterior, segundo a empresa, devido a efeitos da variação cambial, maiores preços e volumes de venda. 
11 - Em 2018, a Vale produziu 384,6 milhões de toneladas de minério de ferro, 5\% a mais do que no ano anterior. Após o desastre de Brumadinho, a companhia suspendeu voluntariamente as operações em dois complexos produtores e foi obrigada pela Justiça a paralisar três outras minas.

12 - As paralisações cortaram um volume equivalente a $24 \%$ de sua produção em 2018, cenário que gera preocupações entre municípios dependentes da mineração e trabalhadores da cadeia produtiva do setor.

13 - A companhia fechou o ano com dívida líquida de US\$ 9,6 bilhões (cerca de $R \$ 37$ bilhões, pela cotação do fim do ano), atingindo a meta de reduzir a dívida abaixo dos US\$10 bilhões (cerca de R\$39 bilhões).

14 - A redução da dívida e o foco na remuneração aos acionistas eram as principais bandeiras do presidente afastado da companhia, Fabio Schvartsman, que assumiu em maio de 2017 e se afastou em fevereiro a pedido da força-tarefa que investiga o rompimento da barragem em Brumadinho.

15 - Em uma das primeiras declarações após o desastre, ele anunciou a suspensão do pagamento de dividendos e de processo de recompra de ações. O balanço de 2018 mostra, porém, que a companhia já havia distribuído aos acionistas antecipadamente mais do que os $25 \%$ do lucro líquido obrigatórios por lei.

16 - Em 20 de setembro, foram pagos $R \$ 7,7$ bilhões a título de juros sobre o capital próprio - segundo a própria Vale, volume "significativamente acima do limite legal", que somaria $\mathrm{R} \$ 6,7$ bilhões, considerando o resultado anual.

\section{Texto 2}

\section{Após quatro anos, Mariana vive descaso e omissão}

Demora nas respostas do Legislativo é devastadora

5.nov.2019 às $2 \mathrm{~h} 00$

\section{Fabiano Contarato}

1 - Nesta terça-feira (5) faz quatro anos que a barragem do Fundão, da mineradora Samarco, em Mariana (MG), rompeu, espalhando 43,7 milhões de $\mathrm{m}^{3}$ de lama tóxica por $663 \mathrm{~km}$ até o mar, no Espírito Santo. Morreram 19 pessoas e o rio Doce. Distritos foram destruídos, milhares de pessoas afetadas, sem água e sem trabalho. Uma perversidade que se prolonga porque a impunidade tem, continuadamente, amargado a vida dos que ficaram: haja vista a recente absolvição de executivos da Vale. 
- Após Mariana e Brumadinho: uma análise discursiva de notícias sobre o descaso

2 - Falamos de executivos em processo cuja peça de acusação sustenta que se omitiram. Informa que, por diversas vezes, receberam alertas sobre os riscos de rompimento da barragem do Fundão. Podem sair "tranquilos" desse pesadelo. As famílias das vítimas, não.

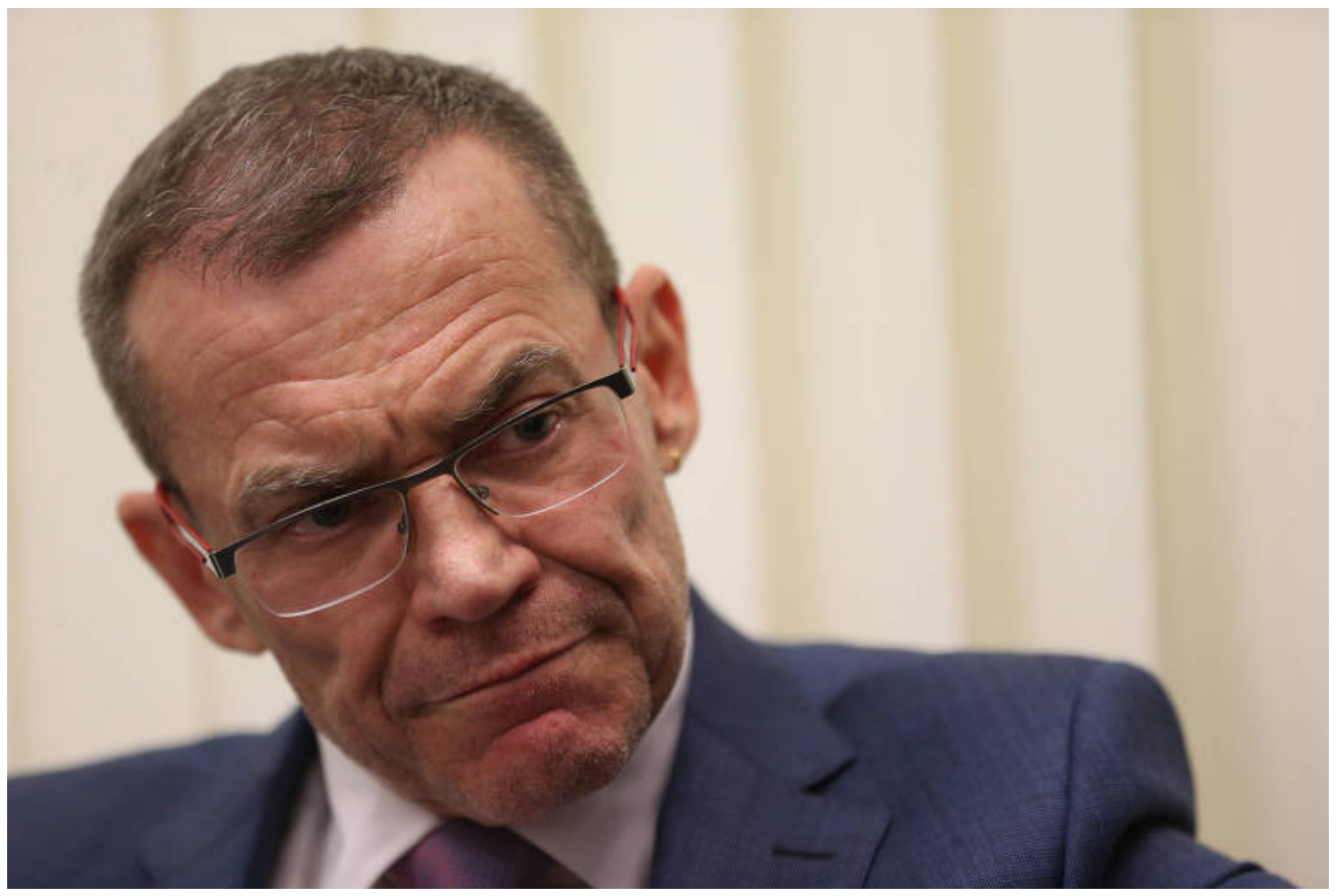

O senador Fabiano Contarato (Rede-ES) em seu gabinete no Senado Federal, em Brasília - Pedro Ladeira - 25.jun.19/Folhapress

3 - Isso é resultado de uma briga em que pessoas pobres, carentes, têm pouquíssimos recursos para enfrentar titãs do direito e altos executivos. Destaque-se que aqui não se coloca em dúvida a capacidade dos defensores públicos e do Ministério Público na assistência à população, pois contra fatos não há argumentos. Mas, infelizmente, no nosso país, não basta ter razão. Chega a ser fantasioso crer em "dê-me os fatos, e eu te darei o direito" tamanha a sensação de impunidade.

4 - O pior é que, em crimes descomunais, sempre vemos uma movimentação enorme de autoridades e de políticos buscando projetar, rapidamente, as suas nobres intenções e soluções. Contudo, o tempo tem mostrado, tragédia por tragédia, que o essencial fica para trás. Tivemos Mariana, depois Brumadinho (MG), em janeiro último - com 252 mortos e 18 desaparecidos. Mas, antes dessas, houve outras em Minas Gerais: 2006 e 2007, a mineradora Rio Pomba Cataguases, em Miraí; 2008, a Companhia Siderúrgica Nacional, em Congonhas; e 2014, Herculano Mineração, em Itabirito. 


\section{Sobreviventes de Mariana (MG)}

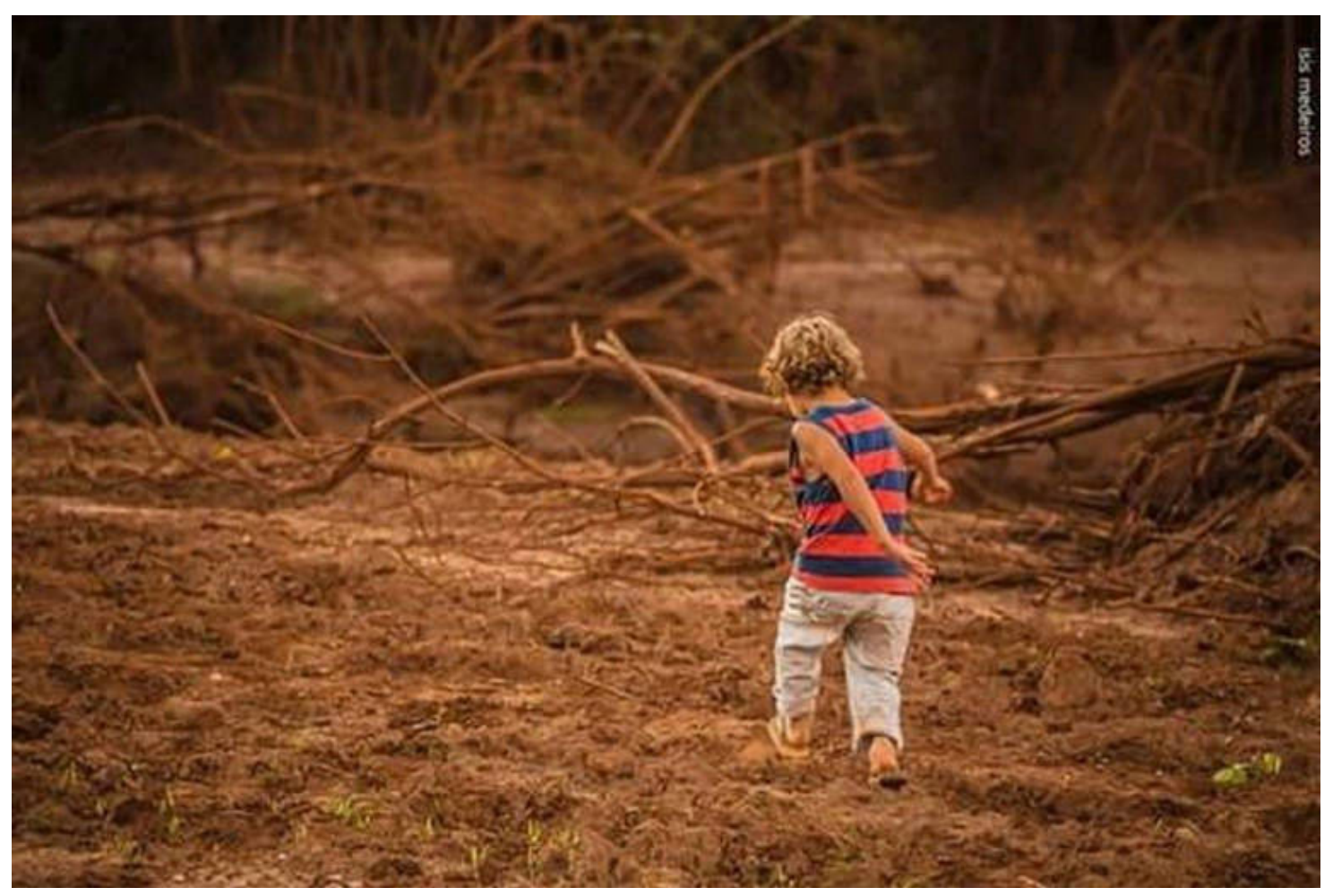

Arthur, filho de Maria do Carmo, caminha em meio à lama que "ilhou" sua casa em 2015, em Mariana; hoje aos 7 anos, ele tem medo de que os rejeitos de Brumadinho voltem Arquivo Pessoal/

5 - Inconteste dizer que a segurança de barragens e a gestão de riscos de desastres são negligenciadas no Brasil. A fiscalização é ridícula. Temos 790 barragens de rejeito de mineração no país. O ministro de Minas e Energia, Bento Albuquerque, em depoimento à Comissão de Meio Ambiente (CMA) do Senado Federal, em maio deste ano, reconheceu: "Não tem barragem segura"; contou ele que dispunha de 16 fiscais para fiscalizar as barragens em todo o país.

6 - Sobretudo, com o que ocorreu em Brumadinho, quais respostas a sociedade brasileira ouviu do Congresso Nacional a respeito dessa insegurança que paira sobre milhares de vidas e a biodiversidade? Que este país endureceria as regras relacionadas às atividades de barragens de rejeitos minerais.

Aprovou-se, no Senado Federal, o projeto de lei n 550/2019 para apreciação, revisão e votação na Câmara dos Deputados. Está lá, desde 20 de março, sem ser votado. 
- Após Mariana e Brumadinho: uma análise discursiva de notícias sobre o descaso

7 - Já a Câmara dos Deputados aprovou três outros projetos - como o de n².787/2019, que "tipifica o crime de ecocídio e a conduta delitiva do responsável por desastre relativo a rompimento de barragem". Somente em 10 de outubro tivemos condições e quórum para aprovar na CMA do Senado Federal - e seguiu à Comissão de Constituição, Justiça e Cidadania (CCJ). Na CMA, continuam para apreciação o PL 2.791/2019, que visa tornar mais seguras as barragens de mineração, e o PL 2.788/2019, que institui a Política Nacional de Direitos das Populações Atingidas por Barragens.

\section{Seis meses do desastre em Brumadinho}

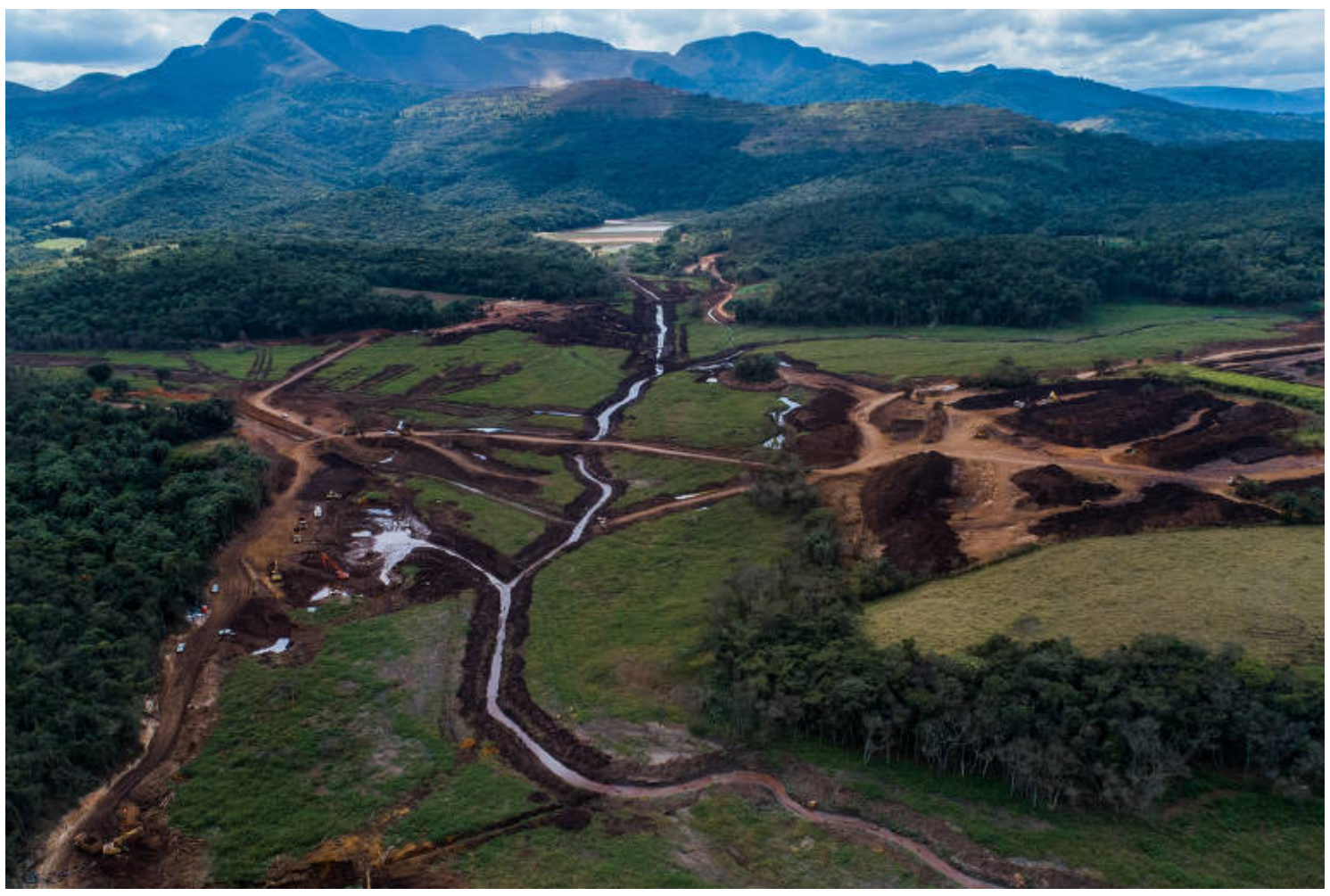

Vista aérea da lama no Parque da Cachoeira, em Brumadinho - Eduardo Anizelli/Folhapress

8 - O que isso evidencia? Diz, claramente, que o Congresso Nacional discursa muito, mas delibera pouco. Não resolve. Não avança na proteção de interesses da sociedade brasileira.

9 - Reunir quórum para votação na CMA do Senado Federal tem sido desafiador. Na maioria das vezes, não conseguimos. Mesmo nas audiências públicas verificamos a presença de poucos senadores. Isso não deveria ocorrer. São 17 membros titulares e 17 membros suplentes! 
10 - A demora nas respostas do Legislativo é devastadora. Explica, em parte, o porquê do desalento da população com a política. O porquê de não confiarmos que, no futuro, poderemos evitar "novas Marianas". Algo precisa, de fato, mudar. Não bastam palavras. É preciso ação de verdade. Não basta dizer-se novo na política. Precisa provar que é.

\section{Fabiano Contarato}

É senador da República (Rede-ES) e presidente da Comissão de Meio Ambiente do Senado Federal

COMO CITAR ESTE ARTIGO: ANDRADE, Maria Lúcia C. V. O.; ARAES, Celia Regina. Após Mariana e Brumadinho: uma análise discursiva de notícias sobre o descaso. Revista do GEL, v. 18, n. 3, p. 264-284, 2021. Disponível em: https:// revistadogel.gel.org.br/

Submetido em: 15/06/2021 | Aceito em: 26/10/2021. 